\title{
A paradox of age in early childhood education: A review of the literature and survey of Australian educators working with three-year-old children
}

\author{
Sheena Elwick ${ }^{1}$ (D) E. Jayne White ${ }^{2}$ \\ Received: 15 October 2020 / Accepted: 6 January 2022 / Published online: 29 January 2022 \\ (c) The Author(s) 2022
}

\begin{abstract}
A paradox concerning age exists in early childhood education (ECE) across many countries today, evident in the literature, curriculum, policy, funding, and provision. This paradox comprises two distinct approaches that call for either a specialised developmental approach to discrete age groups or a generic attitude concerning childhoods with no age distinction at all. This article traces the presence and impact of the paradox of age through an Australian study comprising two components: a review of the literature concerning age; and, a survey undertaken in two states where different treatments of age were evident: NSW and Victoria - with a particular interest in what was happening for three-year-olds. 171 responses were received 102 (NSW) and 69 (Victoria). The review of the literature generated four main themes that when considered in relation to the survey responses revealed the tendency of ECE researchers, policymakers, and educators to situate children within a "discourse of becoming" that focusses attention towards children's maturity and skills, and school readiness. While this discourse has been used productively, its prevalence in this study suggests that many children attending ECE services are likely to experience learning environments that do not always acknowledge the importance of the here and now, or the wealth of experience and knowledge they bring to these environments. This calls attention to the attitudes and assumptions of educators themselves concerning the treatment of younger learners; as well as the constraints and opportunities that policymakers provide for effective provision, and that influence both the nature of and access to ECE.
\end{abstract}

Keywords Paradox of age $\cdot$ Mixed-age $\cdot$ Single-age $\cdot$ Three-year-olds $\cdot$ Policy

\section{Introduction}

A fundamental paradox exists as a result of irreconcilable discourses concerning age in early childhood education (ECE), evident in policy, curriculum, and provision (White, 2020). This

\footnotetext{
Sheena Elwick

selwick@csu.edu.au

1 Charles Sturt University, PO Box 789, Albury, NSW 2640, Australia

2 University of Canterbury, Aotearoa, New Zealand
} 
paradox comprises two distinct approaches that call for either a specialised developmental approach to discrete age groups (and by correspondence, groupings) or a generic attitude concerning childhoods with no age distinction at all. The existing provision of mixed-age (MA) versus single-age (SA) ECE is perhaps the most definitive indication of one stance, or the other, yet such considerations seem virtually absent from contemporary ECE scholarship.

Binaric attitudes towards age are also found in contemporary discussions concerning the educational status and location of three-year-old children in ECE contexts. On the one hand, many OECD countries prioritise education for three-year-olds and frame it as a necessary investment in human capital and future productivity (OECD Starting Strong, 2017). On the other hand, in Australia, a national commitment to the education of three-year-old children is yet to be realised. This is despite research advocating that three-year-old access to a highquality preschool program is important (e.g. Fox \& Geddes, 2016; Pascoe \& Brennan, 2017). At the time of writing, only one Australian state-Victoria-prioritises education for threeyear-old children, with the Victorian Government (2020) investing \$5 billion to ensure they can each access $15 \mathrm{~h}$ per week of a preschool program alongside their four- and five-year-old counterparts. Other states and territories display different attitudes towards education for three-year-old children with some states and territories making it a priority, and others not. For example, in the Australian Capital Territory three-year-old children who are deemed 'priority' children — such as those experiencing vulnerability and disadvantage — can access $15 \mathrm{~h}$ per week of free preschool (Berry, 2019). Likewise, in New South Wales (NSW) some three-year-olds can access a preschool program, with enrolment determined in accordance with complex criteria including the ECE service type and the Socio-Economic Index for Areas, as well as a range of characteristics unique to each child such as their classification as vulnerable and disadvantaged (or not), and their alignment with a range of Priority of Access rules (Council on Federal Financial Relations, 2020). There are reported benefits of the NSW approach. However, it has raised concerns regarding the inequities it generates towards three, four- and five-year-old children in NSW; as well as between these aged children and the same-aged children Australia-wide (e.g. Australian Childcare Alliance, New South Wales, 2019, 2020).

Curriculum documents around the world also share conflicting representations of age - with the treatment of age either explicit: for example, in age specific curriculum such as in Scotland's Pre-Birth to Three document (Learning \& Teaching Scotland, 2010); implicit, such as in New Zealand's Te Whāriki document (Ministry of Education, New Zealand, 2017); or absent, as is the case for Australia's Early Years Learning Framework (Australian Government Department of Employment, Education and Workplace Relations [DEEWR], 2009). Consequently, depending on where early childhood (EC) educators are located across the world, they either have explicit age-based pedagogical guidelines to support their teaching practice; implicit guidelines they may (or may not) interpret and implement; or, no guidelines at all.

It is these conflicting discourses and binaric attitudes towards age in ECE that are the focus of this paper: on the one hand they position age as something that matters, whilst on the other, they position age as something that does not matter. With this paradox in mind, we report on an Australian study undertaken in 2020 by the authors: Age Matters: Age Composition in Early Childhood Education. The study comprised two components: a review of international and national literature concerning age; and, a Qualtrics survey. We start by outlining the review of the literature, including the key questions, the search strategy, and the main themes. We then examine the responses to the survey by EC educators located in 171 ECE services across two Australian states: NSW and Victoria, as they responded to government initiatives concerning three-year-old learners. We specifically asked about changes or adjustments they 
had made (or not made) in response to three-year-old children, as well as the issues they faced in responding to this age group. Here we found a paradox of age playing out in various ways as they navigated their pedagogical responses against perceived constraints concerning buildings, spaces, and funding realities.

\section{Literature review}

The literature review involved a structured process of formulating the review questions, compiling relevant search terms, selecting databases, conducting the literature search, and excluding results that did not match the search criteria. Literature searches were conducted in January and February 2020. The literature review questions were:

$R Q 1$ What is being promoted in relation to age composition in ECE, and why?

$R Q 2$ What are the existing debates about age composition in ECE and what is informing those debates?

$R Q 3$ Who says a particular type of age grouping is best, and why? Why not?

$R Q 4$ What literature is informing the increasing emphasis on three-year old entry into ECE preschool programs?

\subsection{Database searches}

To gather all relevant literature, we implemented both top-down and bottom-up literature searches. Top-down searches involved searching six academic databases using keywords and combinations of keywords: EBSCOhost (Education) comprising five databases-Academic Search Complete; Education Research Complete; ERIC; Psychology and Behavioural Sciences Collection; and, SocINDEX with Full Text. The Taylor and Francis database was also searched. The bottom-up search included reviewing grey literature sources, particularly known sources of potentially relevant information identified by the research team. Potential leads from within those sources were also followed up via Google and Google Scholar. After relevant documents were identified, they were screened at title, abstract, and full-text levels and, if relevant, were added to an Excel file and summarised. All searches were limited to a 1980-2020 date range and studies/documents published in English. Specific keywords for the search included: [Age], [Age Composition], [Age-responsive pedagogies], [developmental difference], [early childhood education], [mixed age composition], [single age composition], [age] AND [ability], [aggregated learning], [composition] AND [single age] AND [mixed age] AND [early childhood education], [grouping] AND [single age] AND [mixed age] AND [early childhood education], [policy] AND [age].

Across the six databases, there were 6514 studies located and scanned and 162 were kept and read further to determine whether to keep or discard. From those 162 studies, 66 were considered relevant to the research questions and were reviewed further in a second stage review, and 2 secondary references were added (total of 68). In that second stage (the final stage), 29 of the 68 studies were discarded; thus, there were a total of 39 studies/papers in the review. The main themes that were generated across these studies/papers are outlined below-further illuminating paradoxes at play. These provide some insight into the thinking that underpins certain treatments of age-on one hand orienting towards developmentally appropriate approaches that suggest younger learners are not 'ready' for certain types of $\mathrm{ECE}$, and focus on separate or single-age provision (SA); while on the other asserting value 
in mixed-age (MA) learning environments. Both poles, it seems, orient ECE provision-sometimes even drawing on the same arguments to make their claims. But, as our review highlights, they are seldom scrutinised concerning the positions they hold.

\subsection{Main themes}

\subsubsection{Academic success, school readiness, and improved developmental outcomes}

Across the reviewed literature, it was evident that age and particularly early-age entry into ECE has received growing attention in recent years as a predictor of academic success, particularly for disadvantaged children (Faulkner \& Coates, 2013; Kohl et al., 2019; Morgan et al., 2016). Consequently, the chase for school readiness has led to the establishment of many mixed-age (MA) classrooms around the world with increasing enrolment rates for three-yearolds (Ansari et al., 2016; Bell et al., 2013). Historically, MA classrooms have been promoted under the light of Bandura's (1986) social learning theory and Vygotsky's (1978) theory of cognitive development, which both maintain that early developmental opportunities primarily arise through social interactions with various peers and educators through observing, scaffolding and modelling behaviours. This is significant as the importance of social skills in cognitive development and collaborative learning is highlighted in several of the reviewed studies (Huľová et al., 2018; Logue, 2006; Park \& Lee, 2015; Umek \& Musek, 1997).

Notably, although theoretical models of MA benefits, such as those proposed by the National Association for the Education of Young Children (Katz et al., 1990), received a lot of attention from successive literature, there is little evidential support or investigation into the mechanisms of such theories. Rather, it appears largely accepted that MA programming will unequivocally lead to improved cognitive development (language, literacy, mathematics and vocabulary), development of prosocial behaviours (sharing, compromise, nurturing), inclusion in more complex and symbolic play, reduced competition, increased self-worth, improved self-regulation and relaxed instructional duties for educators (due to help of older children in groups) (Kallery \& Loupidou, 2016; Katz et al., 1990; Umek \& Musek, 1997).

\subsubsection{Providing a family-like environment}

Resemblance of a family-like environment appears to be an important characteristic of MA groupings to both educators and academics (Hulová et al., 2018; Katz et al., 1990; Rouse, 2015). These theories claim benefits would be available to both the younger and older children in the MA scenario, wherein younger children can model behaviour of the older children, and the older children have the chance to be helpful and patient. For those prioritising a family-like environment, the drawbacks of single-age (SA) grouping were hypothesised as increased pressure and competition, and increased bullying as there is a norm expected of each child (Katz, 1995). However, Katz et al. (1990) and Katz (1995) eluded to the need for investigation into variables and mechanisms, such as optimal group size, age ratio and time spent in these configurations such that younger children are not overwhelmed.

\subsubsection{Lack of and conflicting research concerning child outcomes from various learning environments}

In our review of the literature, there was only a handful of noteworthy studies addressing child outcomes from various learning environments in the last twenty years, none of which 
originate from Australia. One United States (US) study conducted by Ansari et al. (2016), found that four-year-olds in classrooms with three-year-olds exhibited fewer academic gains, equating to as much as 4-5 months' worth of academic development in classes with $45 \%$ represented by three-year-olds. In addition to this, no significant benefits were documented for three-year-old school readiness or social development as previously conjectured. The mechanisms underlying these correlations (or lack thereof) are not fully understood and require more research. It is suggested that the greater social diversity in MA classrooms requires educators to play mediator more often, leaving less time for teaching as such.

Ansari and Purtell (2018) launched the first longitudinal enquiry into peer-effects and teacher continuity-effects in Headstart classrooms over two years in the US. In line with Ansari et al. (2016), this study found that MA classrooms may have deleterious effects for the older children in these classrooms, both first year and second year enrolled. Conversely, greater academic gains were noted for children who transitioned from classrooms where they were the younger ones to SA classrooms in the following year as compared with children who remained in MA classrooms. It is therefore plausible that academic benefits might emerge later when united with same age peers. Teacher continuity has been previously hypothesised as a positive aspect of MA classes enhancing child performance (Gerard, 2005), though it had no apparent effect on the results of the above study (Ansari \& Purtell, 2018). Further assessment of the data retrieved from the Family and Child Experiences Survey 2009 cohort (used for Ansari et al., 2016 and Ansari \& Purtell, 2018) also revealed the amplification of the deleterious effects in MA classrooms with educators without a tertiary degree.

Ansari and Pianta (2019) built on this body of evidence by employing direct assessment methods of academic variables, as opposed to potentially biased teacher reports, and by extending the age range of the sample. This resulted in conflicting evidence, in that significant academic gains were only observed in those younger children that started the year with below-average academic skills, while higher-skilled children generally performed better in classrooms with a greater number of younger classmates. Some executive functioning gains were observed in the younger children in a MA classroom, though no differences in language or literacy variables were found to be significant. Teacher education and experience was noted, however, as a potentially confounding variable, as teachers who participated in Ansari and Pianta (2019) had several years more experience and/or education than teachers participating in the study by Ansari et al. (2016).

Some other studies documented similar findings, in that no significant effect was observed (Bell et al., 2013), or negative associations were made between class heterogeneity and academic development (Moller et al., 2008). These findings were, however, based on teachers' reports of student achievement, which could pose a source of bias or inaccurate comparison to other children (Ansari \& Pianta, 2019). Alternatively, others argue that benefits of peer scaffolding and social modelling might only be observed when the age gap is greater, thereby providing both younger and older classmates for most children (Justice et al., 2019; Katz et al., 1990; Lillard, 2016). For example, Justice et al. (2019) documented greater vocabulary gains for children in MA classrooms in Denmark, but only when the age gap was between 14 and 26 months. Given the availability of educational funding to all families in Denmark, 85\% of one- to two-year-olds are enrolled in ECE programs therefore accommodating for a larger age gap that may not be possible in other countries (Justice et al., 2019). Guo et al. (2014) also documented positive vocabulary gains for the younger children with no observable change for the older children in MA classrooms after adjusting for children's gender, family income, age, and initial vocabulary skills at preschool entry. Though exploratory in nature, this study also noted classroom quality as a potentially moderating factor of the MA-effect on academic gains. 
It is important to note that several of the mentioned studies were undertaken in American Headstart classrooms, wherein $75 \%$ of classrooms are MA as the nations' largest federally funded ECE program (Ansari et al., 2016; Ansari \& Purtell, 2018; Ansari \& Pianta, 2019; Bell, 2013). This could impact the conclusions drawn, as most children in these programs are from low-income families and teacher education is likely to differ to that in other countries. Several studies identify the Montessori model of education as a potential source of longitudinal information, where the age gap in any given classroom is generally three or more years and children are encouraged to learn at their own pace (Katz et al., 1990; Lillard, 2016; Tercek, 1997). Ultimately, further research is required using a range of research methodologies that also consider the diversity of ECE programs and teaching strategies at a local, national and international level.

\subsubsection{Educator beliefs}

The lack of and disparate nature of research concerning child outcomes from MA and SA learning environments suggests that educators' beliefs concerning what is best for particular aged children influence the nature of the ECE program they provide. Recent enquiry into educators' perspectives on the matter of MA versus SA classrooms found that, statistically speaking, more educators prefer homogenous (SA) age classrooms over heterogenous (MA), particularly younger educators (Hulová et al., 2018). This perhaps speaks to the lack of confidence of most educators in programming for multiple skill levels in each class. The main advantages of SA classrooms were thought to be better communication and understanding between children, improved conditions for cognitive development and the opportunity for competition with peers (Huľová et al., 2018). Educators who preferred MA classrooms reported advantages such as the resemblance of the family environment, reduction of competitive pressures and better conditions for social and emotional development (DeBord \& Reguero de Atiles, 1991; Hulová et al., 2018; Tercek, 1997). In long-day-care environments, educators reported similar feelings towards the MA use of the outdoor area, particularly for the development of prosocial behaviours such as sharing and compromise (Rouse, 2015). Educators' main concerns regarding the use of MA classrooms included meeting children's individual needs, and the safety of younger children (DeBord \& Reguero de Atiles, 1991; Hulová et al., 2018; Rouse, 2015; White, 1995; White et al., 2016).

\section{The survey}

Turning to Australia more specifically, the survey was developed in response to concerns voiced by EC leaders and educators navigating (and implementing) age-related government policy and funding documents. In early 2019, the first author was contacted by a NSW community-based preschool director requesting help with developing pedagogical approaches that honoured and supported the three-year-old children attending their service. At that time, community-based preschools in NSW were experiencing high-demand for three-year-old enrolments due to increased state government funding for that age group (e.g. New South Wales Government, 2020). While the aim of that funding, and associated policy, was to provide more children with access to a quality educational program, achieving that aim in practice was not straight-forward. In this instance, many of the three-year-old children had never left the close circle of security of their family before and were unsettled 
being away from their family unit. There were cultural differences in child rearing expectations, and many attended with bottles of milk (with teats) and wearing nappies. Coupled with the complex funding formula that made full funding only available to a three-year-old who attended $15 \mathrm{~h}$ or more per week of a preschool program, the preschool director found themselves facing difficult decisions about three-year-old learners that they felt could easily compromise the children's best interests if taken lightly. It was with this in mind, that we were particularly keen to better understand issues facing ECE leaders and educators when responding to age in two Australian states where different treatments of age were evident: NSW and Victoria-with a particular interest in what was happening for three-year-olds.

\subsection{Instrument}

Because of the complexity of Australian policy and provision of ECE, we undertook a Qualtrics survey with the view to informing a larger study that is currently under review. Ethics was applied for and received from both Charles Sturt University (H19317) and RMIT (CHEAN A 22,425-08/19); and, approval for implementing of the survey was provided by the NSW Early Childhood Education Directorate and the Victorian Department of Education and Training.

To ensure relevancy for the field, the Qualtrics survey was co-developed and trialled with a professional learning group comprising ECE leaders and educators from a range of ECE services located near (and on both sides of) the NSW and Victorian border. The survey included multi-choice and open-ended questions that were based on the original research questions but were revised to ensure relevancy for the NSW and Victorian ECE contexts.

\subsubsection{Participants, sample size and data collection processes}

The survey was sent to all ECE services across NSW and Victoria between the 12th and 27th February 2020 based on the Australian Children's Education and Care Quality Authority (ACECQA) public database. A total of $800 \mathrm{ECE}$ services were invited and 171 fully completed responses were received, comprising a $21 \%$ response rate. $102(60 \%)$ respondents were from ECE services in NSW, and 69 (40\%) were from ECE services in Victoria. Of the overall responses across both states, 127 classified themselves as a service that offered a preschool program delivered by a qualified EC Teacher in the year or two-years before full-time school, and 32 were from Long Day Care (LDC) services generally catering for a wider range of age groups, and that may or may not offer a preschool program delivered by a qualified EC Teacher.

\subsubsection{Analysis}

Quantitative survey results were analysed via SPSS by independent reviewers with market research expertise (see Acknowledgement section for details). The third-party market research team provided an unbiased Executive Summary of the survey results, key insights, and graphical illustrations of every question in the survey. Notably, we were mindful to avoid making claims to represent perspectives as fact or causality-especially as there was a small sample size and the topic had no precedent (Wasserstein et al., 2019). Qualitative survey results were clustered and themed around survey questions by the authors to provide contextual richness to the findings. In the following sections, several key trends that emerged are discussed, along with selected illustrative verbatim excerpts. 


\subsection{Results}

\subsubsection{Age groupings in NSW and Victoria}

Figure 1 displays results of responses to the question "what age groupings do you currently have across your service?' by state (NSW-purple and $n=102$; Victoria-brown and $n$ $=69$ ). The average number of children per age group across each state is also shown. By average number of children per age group we mean the average number attending on a daily basis for that age group. For example, as shown on the left-hand graph in Fig. 1, $1 \%$ of NSW survey respondents reported using 'infants only' age groupings with the sample size being 1 respondent $(n=1)$. Corresponding to this question, the right-hand graph in Fig. 1 shows that this respondent reported that an average number of 15 infants attended the 'infant only' group on a daily basis. This is somewhat different to the situation in Victoria, where the left-hand graph in Fig. 1 shows that $3 \%$ of Victorian respondents $(n=2)$ reported using 'infant only' age groups, with the right-hand graph showing that an average of 5 infants attended these groups on a daily basis.

The graph on the right-hand side of Fig. 1 also shows consistent trends across both states concerning age groupings, with the three- to school-age group being the most prevalent age grouping reported across both states (63\% in NSW and 46\% in Victoria). The left-hand side graph shows that the average number of children in the three- to school-age group was also similar in both states (38 children for NSW and 38.1 for Victoria).

The second highest age grouping reported across both states was the birth to school age group (27\% in NSW and $33 \%$ in Victoria). Not surprisingly, when compared with the average numbers of children per all age groups, the highest overall number of children per group are found in this wider age band (55.4 children per group in NSW and 71 Victoria).

Noteworthy, are the higher average numbers of children per group in the two-years to school-age range for both NSW (55.1) and Victoria (44) despite very few age groupings specifically oriented towards this grouping (7\% NSW and 1\% Victoria). Similar trends are evident, albeit with smaller overall percentages, for birth to three age groupings ( $1 \%$ for both NSW and Victoria) versus average numbers of children for these age groups (16 children in NSW and 10 children in Victoria).

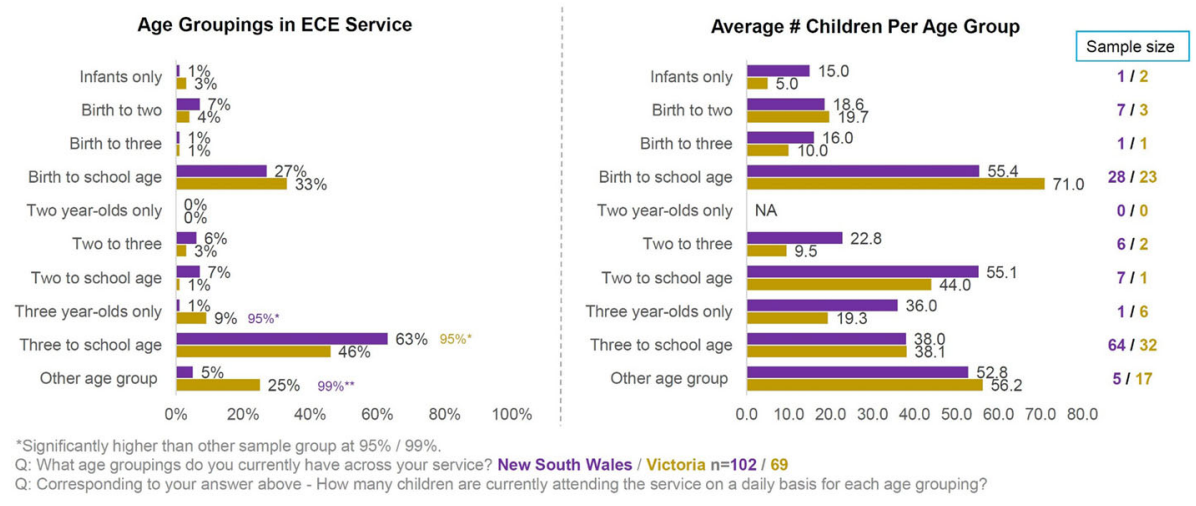

Fig. 1 Age groupings in ECE service + average numbers of children per age group $\times$ state. (Color figure online) 
Also noteworthy is the finding that very few ECE services offered single-age (SA) groupings for three-year-olds only ( $1 \%$ in NSW and $9 \%$ in Victoria). Although small, it is interesting to note that average numbers of three-year-olds specifically grouped together was higher in NSW (36 children per group) compared to 19.3 children in Victoria. This may signal a stronger emphasis in Victoria on placing three-year-old children in mixed-age (MA) groupings with older peers, which corresponds with the data showing that the three to school-age group in Victoria has an average of 38.1 children in the group.

\subsubsection{Reasons for age groupings in NSW and Victoria}

Figure 2 displays results of the related question 'what informed your decision-making process about this [grouping] approach?' by state (NSW $n=102$; Victoria $n=69$ ).

Across both NSW and Victoria, building/space constraints and opportunities (NSW 57\% and Victoria 65\%); and pedagogical reasons (NSW 59\% and Victoria 61\%) were cited as key drivers for age-based decisions. To a lesser extent, staffing was reported as a key influence in both states (NSW 30\% and Victoria 36\%). Also consistent across both states, was the finding that personal beliefs were influencing age-based decisions (NSW 35\% and Victoria 32\%).

Interestingly, when these findings are considered in the light of responses to the open-ended survey question asking respondents to explain how they accommodated for the different age groupings within their service (for example, perhaps two age groups attended on the same day but in different rooms), it became evident that services across both states adopted contextspecific responses and rationalised those responses accordingly. For example:

We have 3 learning environments, with loose age groupings and the 2-3-year-old room, sometimes has a 4-year-old. Towards the end of the year, our baby room is filled with 2-year-olds. We try to keep children in their learning environment for the calendar year.

This is for consistency of care. [NSW Long Day Care (LDC)]

A common theme across both states was the perceived value of MA grouping for facilitating a family-like environment, and a community where the older children mentored or supported

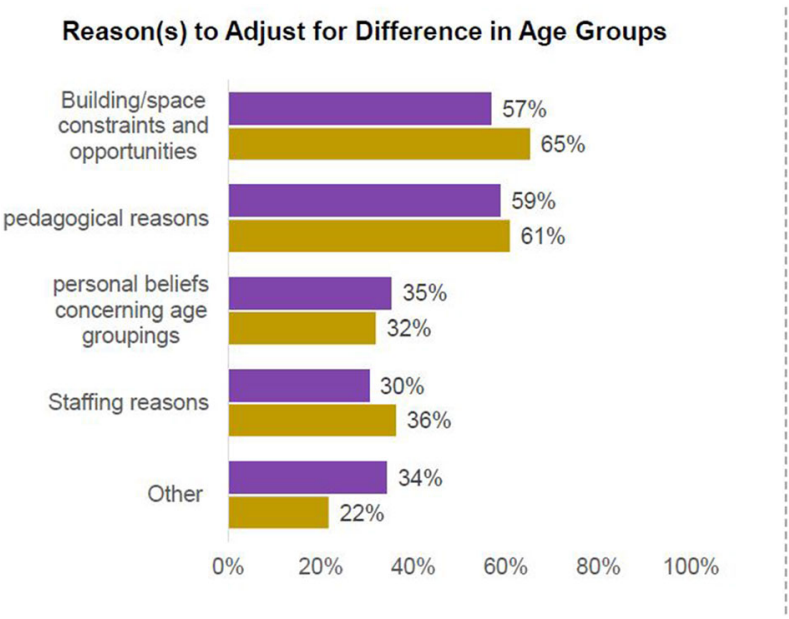

Fig. 2 What informed the decision-making process about grouping approaches? (NSW responses-purple, and Victorian responses-brown). (Color figure online) 
three-year-olds. Respondents from both states also frequently cited philosophical beliefs concerning the importance of MA learning, often summoning play-based learning and social benefits for children as a strong rationale for their groupings. Others cited the "fluidity of children's developmental abilities" and articulated the importance of individual needs and parental preferences as orienting their provision.

Several respondents also described the importance they placed on creating opportunities for MA experiences even when age specific rooms were offered. They often achieved this through shared outdoor areas where different aged children could spend time together. As respondents from one NSW service stated, "it benefits all children to be in an environment with 3-5 year olds". This view was also shared by other respondents more broadly. For example:

Whilst we place children chronologically in their classes, we encourage them to play together in the outdoors. Also, as we are a centre that promotes the inclusion of all children regardless of their abilities, we rely on funding to support the rooms where the children have been placed. As part of the funding protocols children have to be placed with their chronological cohort. We would not manage without funding to support these children. [NSW LDC]

A smaller group of survey respondents across both states were protective of distinct SA groupings-believing them to be necessary "for concentration and learning reasons" with several citing an "extensive divide of developmental stages of each child". Separation anxiety and toilet training were also cited as reasons for age-segregation. Many of these respondents were much focussed on preparation for school - keen to ensure that children were "in their correct school entry cohort" and accommodating the schooling calendar year, with respondents from one Victorian service stating:

We are philosophically opposed to combining 3's and 4's and would never do it to deliver a 3's program [our emphasis].

Similarly, respondents from one NSW service suggested that separate age groupings for three-year-olds would:

... support the development of skills without the added pressure of keeping up with the group. Children are typically able to keep up with their own age group at their own pace.

Several respondents also believed that age specific groupings made it easier for them to access specialist support services, although they did not explain why. It seemed that most respondents across both states were working hard to maintain these polarised principles, while also responding to Federal and State Government demands.

\subsubsection{Grouping adjustments over time}

When asked if their age groupings had changed over time, more than half of the respondents across both states indicated that their age groups had not changed (NSW 53\% and Victoria $59 \%$ ). The survey did not require respondents who answered 'no' to this question to explain their reasoning for maintaining the same age groupings over time. However, respondents in the remaining $47 \%$ (NSW) and $41 \%$ (Victoria) services whose groupings had changed over time were asked to explain how. Reasons varied, but many spoke a great deal about the need to prioritise four-year-old children because of funding. Three-year-old children, on the other 
hand, were often slotted in around four-year-old enrolments on either different days or times, different rooms, or as integrated "top-ups" to four-year-old enrolments. For example:

Traditionally we had a 3-year-old class and a 4-year-old class. In 2016 to meet universal access requirements for 4-year-olds, our 3-year-old class became a 3-5-year-old class, with priority given to children in the year before school as per funding guidelines. This can mean 3-year-olds miss out on a position dependant on the number of 4-year-olds on our waiting list. [NSW Preschool]

And:

We used to have a specific 3-year-old 1-day group, but with the introduction of Start Strong (15 hours attendance per week) and with increasing demand, we have not been able to offer a 3 -year-old position for over 5 years. In the past we would have children attend for 2 to 3 years, now most children attend for 1 year and some 2. [NSW Preschool]

Similar complexities resulting from the prioritising of four-year-olds in government funding were also described by respondents located in one Victorian service:

We have $2 \times 4$-year-old kindergarten ${ }^{1}$ groups. We 'top-up' with Pre-kinder (3-year-old kinder) for 3 hours on two days. The children are in the same room, but we have an additional staff member when we have the 3 -year-olds in attendance.

\subsubsection{Challenges and changes in relation to three-year-olds}

Figure 3 highlights noteworthy findings in response to the questions: 'what do you see as the biggest challenges for you in catering for three-year-olds specifically?' and 'what, if anything have you changed in your service to better accommodate three-year-olds?' Interestingly, despite structural changes being identified as a significant challenge for Victoria (39\%), only $22 \%$ of Victorian respondents had made structural changes to better accommodate threeyear-old learners. Likewise, although financial challenges to accommodate three-year-old children was cited by Victorian respondents as their third biggest challenge (32\%), only $13 \%$ had made financial changes to accommodate three-year-old children.

Regarding finances, respondents from both NSW and Victoria re-articulated that their decisions were heavily influenced by four-year-old policy and funding prioritisations. For example:

Because the 4-5-year-old group attends 4 days across the week this restricts the 3-yearold group to one day. PLUS the 3-year-old group is not funded and so to be affordable the children attend for one 3 hour session/week. [Victorian Kindergarten]

And:

Unfortunately, as we give priority to 4-year-olds we often do not have the capacity to enrol 3-year-olds-so many children are missing out. [NSW Preschool]

There were also strong feelings of inequity in current funding arrangements that did not serve "in the best interests of all children in Australia regardless of their age".

\footnotetext{
1 NSW and Victoria have different names for preschool services offered by a qualified EC Teacher in the year or two before full-time school. In New South Wales preschool services are typically known as preschools whereas in Victoria, preschools can be known as preschools, kindergartens, or preschool programs in LDC centres (Raising Children Network, 2018).
} 

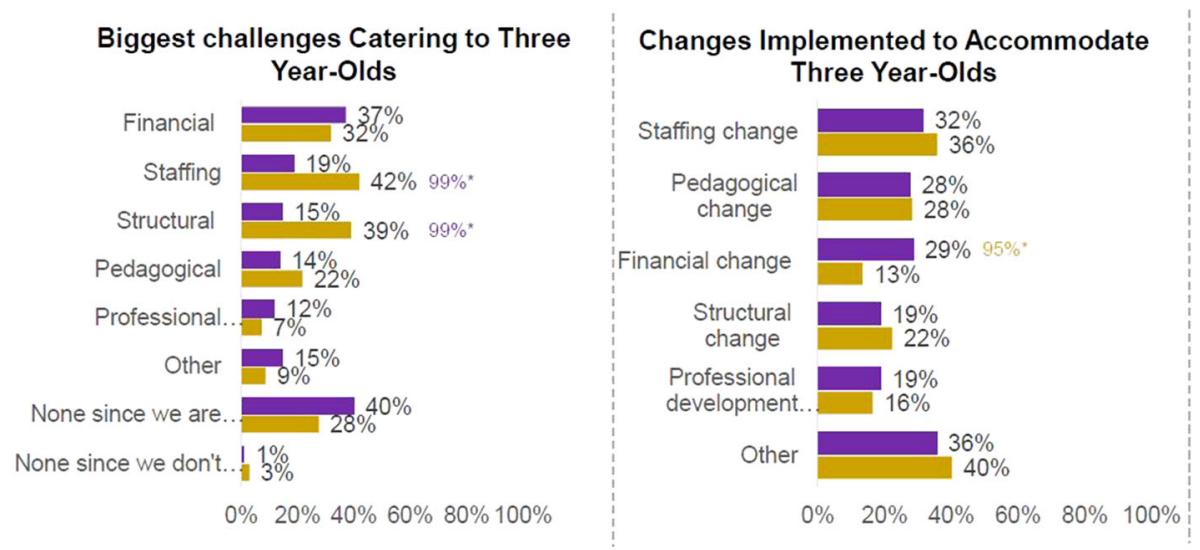

Fig. 3 Challenges faced and implemented concerning three-year-olds specifically across states (NSW responses-purple; Victoria responses-brown). (Color figure online)

Finally, when asked what would best support them in accommodating three-year-old children in their service, respondents from both NSW and Victoria commented on the need for specialised professional development and curriculum guidance to work effectively with three-year-old learners. For example:

We need a new chapter of the EYLF just identifying three-year-olds. Their brain development and how we can support them to be 3 to the best of their ability. I have read some government reports which capture some of this but to have it distilled in a commonly used document for those "on the floor" would be helpful. [NSW Preschool]

\section{Discussion: Playing out the paradox}

One thing that immediately comes to mind when exploring the results of this study is that the topic of age in ECE is one that evokes a vast range of complementary and contrasting opinions from researchers, policymakers, and EC leaders and educators; with varying provision arising as a consequence. Our review of the international and national literature resulted in four main themes: academic success, school readiness, and improved developmental outcomes; providing a family-like environment; lack of and conflicting research concerning child outcomes from various learning environments; and, educator beliefs.

The first two of these themes-academic success, school readiness, and improved developmental outcomes, along with providing a family-like environment-were also evident in the survey responses and were key drivers of age-based decisions made by EC leaders and educators located in NSW and Victoria. Indeed, and paradoxically, school readiness was cited by proponents of both MA and SA classrooms as a benefit of their chosen approach. Likewise, the provision of a family-like environment was important to most survey respondents regardless of their preference for MA or SA classrooms, with many respondents stating that a family environment enabled older children to mentor and support the development and learning of younger children. In fact, the words offered by respondents at one service, "it benefits all children to be in an environment with 3-5 year olds", were echoed by many. 
In services that exclusively used SA classrooms indoors, they often achieved a family-like environment by providing children with MA opportunities outdoors.

Speculatively, these ways of rationalising the benefits and outcomes of MA or SA learning environments assume that older children can model appropriate behaviour to younger children, and that younger children need help in this regard. Moreover, they assume that younger children (or, indeed, all aged children) have the ability to communicate in ways that enable the supposed outcomes to be realised. Concerningly, these ways of thinking about children situates them within a "discourse of becoming" that, at least in part, focusses on children's maturity (or lack thereof) and ensuring children possess the 'right' skills in time to be ready for school and beyond. This, in turn, establishes an environment in which younger children are easily perceived to be lacking in maturity and skills and are located within ECE services accordingly. Survey responses that illustrate this point can be found in statements emphasising an "extensive divide of developmental stages of each child", along with a need to segregate children to manage "separation anxiety" and "toilet training". It is responses such as these that compel us to consider broader questions such as: What is 'teaching' in an ECE context? Does it involve changing nappies, managing toilet training, and separation anxiety? Or, as suggested by the Ansari et al. (2016) study, does mediating around play and engaging in conflict resolution leave less time for 'teaching' as such? These are all important discussions that are yet to be had, despite their potential to lead to more responsive educational spaces for children of all ages.

The third theme that emerged from the literature review - a lack of and conflicting research concerning child outcomes from various learning environments-is also interesting to consider in the light of the survey responses. What overwhelmingly stood out in the findings of the literature review was the conflicting evidence regarding the impact of heterogenous (MA) or homogeneous (SA) learning environments on children's development and learning. Yet, as noted above, many survey respondents claimed MA classrooms were beneficial for children of all ages, leading to improved academic outcomes, school readiness, and developmental outcomes. This is despite contrary evidence in the literature that the greater social diversity in MA classrooms may have deleterious effects on older children; and, that there are no significant benefits documented for school readiness or social development (Ansari et al., 2016). Additionally, both Ansari et al. (2016) and Ansari and Purtell (2018) revealed the amplification of the deleterious effects in MA classrooms with educators without a tertiary degree. This finding is particularly relevant to the Australian context where a tertiary degree is typically only required for EC Teachers working with children enrolled in a government funded preschool program, which as noted earlier, is mostly only made available to four-year-old children (McFarlane \& Lewis, 2012). Notably, there are also concerns about the nature of the training that educators receive, with many authors noting that insufficient attention is given in non-tertiary qualifications to the developmental and pedagogical needs of young children (Chu, 2016).

When these concerns are viewed in conjunction with the final theme that emerged from the literature review - educator beliefs - it suggests that much of what is happening for children in ECE learning environments may not be responsive to their developmental and pedagogical needs. This stresses the need for deeper consideration and debate of what can be done to ensure the presence of age-responsive practices that promote rather than inhibit the inclusion of all children, regardless of age. Important to this debate is the survey finding that

\footnotetext{
2 We thank a reviewer of an earlier version of this paper for directing our attention to this discourse and associated points of discussion. We are also influenced by opposing views of becoming that exceed the certainty of 'being' "in favour of uncertain, yet appreciative stances of engagement which have yet to find their place in curriculum to their fullest extent" (White \& Mika, 2019, p. 29).
} 
building/space constraints and opportunities, and funding considerations are key drivers of age-based decisions at a localised level in NSW and Victorian ECE contexts. It was here that some of the impacts of being a child aged three in NSW or Victoria were most evident, with some three-year-old children being granted access to an educational program alongside their four-year-old counterparts, and other three-year-old children not. More concerningly, it seems that binaric treatments of age at a policy and funding level are creating a situation-in these two Australian states at least-wherein many three-year-olds may find themselves 'commodified' insofar as they are being slotted in around four-year-old enrolments on either different days or times, different rooms, or as integrated "top-ups" to four-year-old enrolments. The consequences of this commodification are perhaps seen in the limited structural changes that had been made to better accommodate three-year-old learners in Victoria, despite structural reasons being identified as a significant challenge.

Nevertheless, it is worth noting that these decisions were often portrayed as difficult decisions by the survey participants. This is a stark reminder of the concerns voiced by the NSW community-based preschool director who was involved in the co-development of the survey. For them, along with many of the survey respondents, there were strong feelings that there was much more work to be done to welcome three-year-old children into ECE environments as learners in their own right—-both as peers of four-year-olds, and as learners who bring a wealth of knowledge and capabilities that can enrich the lives of others.

A potential limitation of the study is that the graphs displayed in Fig. 1 do not separate ECE services that provide for children aged birth-to-five, from those that only offer a preschool program delivered by a qualified EC Teacher in the year or two-years before full-time school. Consequently, the data reported here may not reflect the complexity of the existing ECE sector in Australia. Nonetheless, in the context of the key focus of this paper-the paradox of age-providing additional detail regarding the complexity of the Australian ECE sector would likely highlight further paradoxes (especially across service types) rather than diminish those reported. Additionally, it is clear from the reviewed literature that although this present study has focused on two states in Australia, paradoxical treatments of age exist across the globe.

\section{Conclusion}

Throughout this paper we have argued there is a paradox concerning age in ECE across many countries today, evident in the literature, curriculum, policy, funding, and provision. Its presence and associated impact were subsequently traced through an Australian study undertaken by the authors: Age Matters: Age Composition in Early Childhood Education. The study comprised two components: a review of international and national literature concerning age; and, an Australian-based Qualtrics survey undertaken in two states where different treatments of age are evident: NSW and Victoria-with a particular interest in what was happening for three-year-olds.

Our review of the international and national literature resulted in four main themes: academic success, school readiness, and improved developmental outcomes; providing a family-like environment; lack of and conflicting research concerning child outcomes from various learning environments; and, educator beliefs. When considering the survey responses in the light of these themes multiple key points demanding further discussion and debate emerged. These included the tendency of ECE researchers, policymakers, and educators to situate children within a "discourse of becoming" that often focusses attention towards 
children's maturity and skills, and school readiness. While this discourse has been used productively at times-for example, in Australia's Early Years Learning Framework (DEEWR, 2009), its prevalence in this study suggests that many children attending ECE services are likely to experience learning environments that do not always acknowledge the importance of the "here and now" (p. 7), or the wealth of experience and knowledge that they bring to these environments. Instead the prevailing message that orients provision appears to be more concerned with preparation for school and the 'not yet ready' three-year-old who must either learn to fit into existing practices, structures and settings; or wait until they turn four to enter into 'real' learning contexts.

Notwithstanding the binaries at play concerning EC educators' attitudes towards MA or SA provision, further paradoxes concerning age are evident in policy and provision. On the one hand, a strong desire to see three-year-olds in ECE is purported, yet on the other, three-year-olds across several states (and by association, in ECE services) receive limited access to education in comparison with their older peers. On the one hand, notions of 'quality ECE' are advanced for three-year-olds, yet funding is not equitable by state; and educators' qualifications appear to diminish in accordance to children's age. EC educators expressed an urgent need for professional development to navigate practices that were more inclusive of younger learners, but none was available to them. Those who held the view that SA (or partial SA) was necessary, perceived that certain types of buildings were unsuitable; yet there appeared to be no plans to either make these adjustments or to explore alternative possibilities. Thus, even if EC educators wanted to explore different types of provision that would cater effectively for three-year-olds alongside their peers, it was not always possible to do so.

Taking all these factors into account there is a compelling need for further research that will identify 'what works' and 'why' for three-year-old learners in ECE services. This calls attention to the attitudes and assumptions of EC educators themselves concerning the treatment of younger learners; as well as the constraints and opportunities that policymakers provide for effective provision, and that influence both the nature of and access to ECE. At the centre of these considerations, and actions, lies the paradox of age that orients what is valued, who is granted access, and what is offered (to whom) as a consequence. Importantly, this need for further research is relevant for other countries around the world, since the literature suggests that the absence of thought concerning younger learners in ECE is not unique to Australia (e.g. White \& Redder, 2019).

\section{Ethical approval}

Charles Sturt University (H19317) and RMIT (CHEAN A 22425-08/19); and, approval for implementing of the survey was provided by the NSW Early Childhood Education Directorate and the Victorian Department of Education and Training.

Acknowledgements The authors wish to acknowledge Charles Sturt University for their full funding of the literature review and their partial funding of the survey design, dissemination, and analysis. We would also like to fully acknowledge our Research Assistant, Brianna Lambert, who completed the literature review component of the study. Thanks also to Qualtrics and Strop Insights (www.stropinsights.com) for their independent analysis; and, the members of the 'Reclaiming the Early Years' professional learning group, who have since provided the incentives for us to pursue this work.

Funding Open Access funding enabled and organized by CAUL and its Member Institutions. This research was partially funded by Charles Sturt University. 
Open Access This article is licensed under a Creative Commons Attribution 4.0 International License, which permits use, sharing, adaptation, distribution and reproduction in any medium or format, as long as you give appropriate credit to the original author(s) and the source, provide a link to the Creative Commons licence, and indicate if changes were made. The images or other third party material in this article are included in the article's Creative Commons licence, unless indicated otherwise in a credit line to the material. If material is not included in the article's Creative Commons licence and your intended use is not permitted by statutory regulation or exceeds the permitted use, you will need to obtain permission directly from the copyright holder. To view a copy of this licence, visit http://creativecommons.org/licenses/by/4.0/.

\section{References}

Ansari, A., Purtell, K., \& Gershoff, E. (2016). Classroom age composition and the school readiness of 3and 4-year-olds in the head start program. Psychological Science, 27(1), 53-63. https://doi.org/10.1177/ 0956797615610882

Ansari, A., \& Purtell, K. M. (2018). Continuity and changes in classroom age composition and achievement in head start. Journal of Applied Developmental Psychology, 58, 86-95. https://doi.org/10.1016/j.appdev. 2018.07.002

Ansari, A., \& Pianta, R. (2019). Classroom age composition and the early learning of pre-schoolers. The Journal of Educational Research, 112(2), 234-242. https://doi.org/10.1080/00220671.2018.1514356

Australian Childcare Alliance, New South Wales. (2019). Submission to the review of the universal access national partnership. https://nsw.childcarealliance.org.au/images/Documents/Submissions/201910-06_-_Submission_to_Nous_Group_re_UNAP_Review-merged-pages.pdf

Australian Childcare Alliance, New South Wales. (2020). NSW Government's free preschool decision exposes own massive and unfair treatment and inconsistencies. https://nsw.childcarealliance.org.au/ news/805-nsw-government-s-free-preschools-decision-exposes-own-massive-and-unfair-treatmentand-inconsistencies

Australian Government Department of Employment Education and Workplace Relations. (2009). Belonging, being and becoming: the early years learning framework for Australia. https://k10outline.scsa.wa.edu. au/_data/assets/pdf_file/0003/4629/EYLF_complete_doc.pdf

Bandura, A. (1986). Social foundations of thought and action. Prentice-Hall Inc.

Bell, E. R., Greenfield, D. B., \& Bulotsky-Shearer, R. J. (2013). Classroom age composition and rates of change in school readiness for children enrolled in head start. Early Childhood Research Quarterly, 28(1), 1-10. https://doi.org/10.1016/j.ecresq.2012.06.002

Berry, Y. (2019). Setting the foundations for every child's success. Media Release. https://www.cmtedd.act. gov.au/open_government/inform/act_government_media_releases/yvette-berry-mla-media-releases/ 2019/setting-the-foundations-for-every-childs-success

Chu, M. (2016). What's missing in most of our early childhood degrees? Focusing more deeply on relationships and learning with infants, toddlers, and their families. Journal of Early Childhood Teacher Education, 37(4), 264-281. https://doi.org/10.1080/10901027.2016.1241966

Council on Federal Financial Relations. (2020). New South Wales implementation plan: National partnership on universal access to early childhood education - 2018 -2020. Retrieved from: http://www. federalfinancialrelations.gov.au/content/npa/education/national-partnership/2020-UAECE-NSW.pdf

DeBord, K. B., \& Reguero de Atiles, J. T. (1991). Teacher perception of mixed-age groupings of children. 1-22. https://files.eric.ed.gov/fulltext/ED360047.pdf

Faulkner, D., \& Coates, E. A. (2013). Early childhood policy and practice in England: Twenty years of change. International Journal of Early Years Education, 21(2-3), 244-263. https://doi.org/10.1080/09669760. 2013.832945

Fox, S., \& Geddes, M. (2016). Preschool - two years are better than one: Developing a universal preschool program for Australian 3 year olds - evidence, policy and implementation. Mitchell Institute Policy Paper No. 03/2016. Mitchell Institute.

Gerard, M. (2005). Bridging the gap: Towards an understanding of young children's thinking in multiage groups. Journal of Research in Childhood Education, 19(3), 243-250. https://doi.org/10.1080/ 02568540509595068

Guo, Y., Tompkins, V., Justice, L., \& Petscher, Y. (2014). Classroom age composition and vocabulary development among at-risk preschoolers. Early Education and Development, 25(7), 1016-1034. https://doi. org/10.1080/10409289.2014.893759 
Huová, Z., Rochovská, I., \& Klein, V. (2018). The issue of age homogeneity in groups from the kindergarten teacher's perspective. The New Educational Review, 53(3), 203-215. https://doi.org/10.15804/tner.2018. 53.3.17

Justice, L. M., Logan, J. A., Purtell, K. A., Bleses, D., \& Højen, A. (2019). Does mixing age groups in early childhood education settings support children's language development? Applied Developmental Science, 23(3), 214-226. https://doi.org/10.1080/10888691.2017.1386100

Kallery, M., \& Loupidou, T. (2016). Learning science in small multi-age groups: The role of age composition. International Journal of Science Education, 38(9), 1570-1590. https://doi.org/10.1080/09500693.2016. 1201871

Katz, L., Evangelou, D. \& Hartman, J. A. (1990). The case for mixed-age grouping in early education. National Association for the Education of Young Children, 1-76. https://files.eric.ed.gov/fulltext/ED326302.pdf

Katz, L. (1995). The benefits of mixed-age grouping. ERIC Digest, 1-6. https://files.eric.ed.gov/fulltext/ ED382411.pdf

Kohl, K., Willard, J. A., Agache, A., Bihler, L. M., \& Levendecker, B. (2019). Classroom quality, classroom composition, and age at entry: Experiences in early childhood education and care and single and dual language learners' German vocabulary. AERA Open. https://doi.org/10.1177/2332858419832513

Learning and Teaching Scotland. (2010). Pre-birth to three: Positive outcomes for Scotland's children and families. https://stramash.org.uk/wp-content/uploads/2018/08/elc2_prebirthtothreebooklet.pdf

Lillard, A. S. (2016). Montessori: The science behind the genius. Oxford University Press.

Logue, M. E. (2006). Teachers observe to learn: Differences in social behaviour of toddlers and preschoolers in same-age and multiage groupings. Young Children, 61(3), 70-76.

MacFarlane, K., \& Lewis, P. (2012). United we stand: Seeking cohesive action in early childhood education and care. Contemporary Issues in Early Childhood, 13(1), 63-73. https://doi.org/10.2304/ciec.2012.13. 1.63

Ministry of Education, New Zealand. (2017). Te Whāriki Early childhood curriculum. https://education.govt. nz/assets/Documents/Early-Childhood/ELS-Te-Whariki-Early-Childhood-Curriculum-ENG-Web.pdf

Moller, A. C., Forbes-Jones, E., \& Hightower, D. A. (2008). Classroom age composition and developmental change in 70 urban preschool classrooms. Journal of Educational Psychology, 100(4), 741.

Morgan, P. L., Farkas, G., Hillemeier, M. M., \& Maczuga, S. (2016). Science achievement gaps begin very early, persist, and are largely explained by modifiable factors. Educational Researcher, 45(1), 18-35. https://doi.org/10.3102/0013189X16633182

New South Wales Government. (2020). Start strong guidelines for community preschools. https://education. nsw.gov.au/early-childhood-education/operating-an-early-childhood-education-service/grants-andfunded-programs/start-strong/start-strong-guidelines

OECD. (2017). Starting Strong 2017: Key OECD indicators on early childhood education and care. OECD Publishing. https://doi.org/10.1787/9789264276116-en

Park, J., \& Lee, J. (2015). Dyadic collaboration among preschool-age children and the benefits of working with a more socially advanced peer. Early Education and Development, 26(4), 574-593. https://doi.org/ 10.1080/10409289.2015.995567

Pascoe, S., \& Brennan, D. (2017). Lifting our game: Report of the review to achieve educational excellence in Australian schools through early childhood interventions. Retrieved from https://education.nsw.gov. $\mathrm{au} / \mathrm{content} / \mathrm{dam} / \mathrm{main}$-education/early-childhood-education/whats-happening-in-the-early-childhoodeducation-sector/media/documents/Lifting-Our-Game-Final-Report.pdf

Raising Children Network. (2018). Preschool in your state. Retrieved October 8, 2020, from https:// raisingchildren.net.au/preschoolers/play-learning/preschool/preschool-in-your-state

Rouse, E. (2015). Mixed-age grouping in early childhood - creating the outdoor learning environment. Early Child Development and Care, 185(5), 742-751. https://doi.org/10.1080/03004430.2014.953138

Tercek, P. M. (1997). Mixed-age grouping in kindergarten: A best case example of developmentally appropriate practice or Horace Mann's worst nightmare? Master's Research Practicum, Malone College. https://eric. ed.gov/?id=ED414086

Umek, L. M., \& Musek, P. (1997). Symbolic play in mixed-age and same-age groups. European Early Childhood Education Research Journal, 5(2), 47-59. https://doi.org/10.1080/13502939785208071

Victorian Government. (2020). Three-year-old kindergarten for Victoria. https://www.vic.gov.au/three-yearold-kindergarten-victorians

Vygotsky, L. S. (1978). Mind in society: The development of higher psychological processes. Harvard University Press.

Wasserstein, R. L., Schirm, A. L., \& Lazar, N. A. (2019). Moving to a world beyond “p < 0.05.” The American Statistician, 73, 1-19. https://doi.org/10.1080/00031305.2019.1583913 
White, E. J. (1995) A well-orchestrated ballet, or a production line? Age compositions in infant childcare centres. In: Proceedings of the 6th early childhood convention: Tamaki makaurau: Their heritage, our horizon: Nga paewai, he ahunga he takahitanga ma tatou (pp. 183-206). Auckland.

White, E. J., Peter, M., \& Ranger, G. (2016). Two year olds in ECE: A policy issue for New Zealand? Early Childhood Folio, 20(2), 10-15.

White, E. J., Mika, C. (2019). A genealogy of becoming (and being) in the first 1000 days. In: M. Gradovski et al. The first 1000 days of early childhood: Becoming (pp. 17-31). Springer.

White, E. J., \& Redder, B. (2019). Age-responsive pedagogies: 'Preschool' teachers interrogate their dialogues with and about two-year-olds. Report to Teaching and Learning Research Initiative. Wellington, New Zealand.

White, E. J. (2020). The paradox of age for the infants and toddlers of Te Whāriki. In A. Gunn \& J. Nuttal (Eds.), Weaving te whäriki: aotearoa New Zealand's early childhood curriculum framework in theory and practice, 3rd edn (pp. 105-114). NZCER Press.

Publisher's Note Springer Nature remains neutral with regard to jurisdictional claims in published maps and institutional affiliations. 